\title{
SINERGIA
}

REVISTA DO INSTITUTO DE CIÊNCIAS ECONÔMICAS, ADMINISTRATIVAS E CONTÁBEIS (ICEAC)

\section{ASSIMETRIA NA TRANSMISSÃO DOS PREÇOS: RESULTADOS PARA O MERCADO DA GASOLINA DAS MAIORES CIDADES DO RIO GRANDE DO SUL ENTRE 2005 E 2018}

\author{
RONALDO TORRES \\ FERNANDA CIGAINSKI LISBINSKI ** \\ REISÓLI BENDER FILHO***
}

\begin{abstract}
RESUMO
O trabalho buscou identificar a presença de transmissão assimétrica nos preços da gasolina para as cidades de grande parte do Rio Grande do Sul, entre 2005 e 2018, considerando o modelo “upstream”, que analisa a transmissão dos preços do varejo para o atacado. A metodologia consistiu na aplicação de um modelo de correção de erros (MCE) nas séries de preços do varejo "postos de combustíveis" e nas series de preços do atacado "distribuidores". Os resultados indicaram que, para o curto prazo, $77,77 \%$ das cidades analisadas apresentaram algum tipo de transmissão assimétrica dos preços enquanto que, para o longo prazo, 22,22\% das cidades apresentaram tal falha de mercado. Evidências que permitem concluir que as maiores cidades do Rio Grande do Sul apresentam problemas informacionais quanto ao repasse das variações aos preços da gasolina com potenciais perdas aos consumidores.
\end{abstract}

Palavras-chave: Transmissão assimétrica de preços; Gasolina; Modelo de correção de erros; Cidades do Rio Grande do Sul.

\section{ABSTRACT}

The study sought to identify the presence of asymmetric transmission in gasoline prices for large cities in Rio Grande do Sul, between 2005 and 2018, considering the "upstream" model, which analyzes the transmission of retail prices to wholesale. The methodology consisted of the application of an error correction model (MCE) in the retail price series "gas stations" and wholesale price series "distributors". The results indicated that, for the short term, $77.77 \%$ of the cities analyzed presented some type of asymmetric transmission of prices while, for the long term, $22.22 \%$ of the cities presented such market failure. Evidence to conclude that the largest cities in Rio Grande do Sul have informational problems regarding the transfer of variations in gasoline prices with potential losses to consumers.

Keywords: Asymmetric price transmission; gasoline; Error Correction Model; cities of Rio Grande do Sul.

Recebido em: 30-08-2020 Aceito em: 16-07-2021

\section{INTRODUÇÃO}

Os custos sobre o consumo da gasolina sempre requerem grande atenção por parte do mercado consumidor, especificamente quando a mudança se reflete em alterações positivas nos preços finais. Esse aumento provoca descontentamento ao consumidor devido ao fato de a parcela da representação do consumo da gasolina ser significativa em relação à renda agregada que, para o ano de 2018, ficou perto de 3,5\% no estado do Rio Grande do Sul, de acordo com dados da Agencia Nacional do Petróleo (ANP, 2018a).

A forma como as variações dos custos é transmitida aos preços, ao longo da cadeia produtiva, é um debate recorrente, sobremaneira, no mercado de combustíveis, pois, frequentemente, essas transmissões ocorrem de maneira a beneficiar o ofertante "postos de combustíveis" e, em contrapartida, se tem uma redução significativa da renda por parte dos consumidores.

Esta é uma característica das estruturas de mercado cuja transmissão de preços ocorre de forma assimétrica, repassando, de forma mais rápida ou intensa, às variações, quando os preços dos combustíveis estão subindo, do que quando eles estão se reduzindo. Na literatura, existem diversos trabalhos que estudam o comportamento assimétrico dos agentes em respostas a alterações nos insumos. Cabe destacar os estudos realizados, na sintetização destes trabalhos, por Meyer e Von Cramon-Taubadel (2004) e Frey e Manera (2007).

\footnotetext{
* Mestrando no Programa de Pós-Graduação em Organizações e Mercados da Universidade Federal de Pelotas (UFPEL). Graduado em Ciências Econômicas pela Universidade Federal de Santa Maria (UFSM). E-mail: torresronaldo@yahoo.com.br

" Doutoranda em Economia Aplicada pela Universidade de São Paulo (USP). Mestre em Economia e Desenvolvimento pela Universidade Federal de Santa Maria (UFSM).

"*t* Doutor em Economia e Relações Internacionais pela Universidade Federal de Santa Maria (UFSM). Professor da Universidade Federal de Santa Maria (UFSM).
} 
Em âmbito nacional, há poucos estudos que buscam identificar como acontecem os repasses nos mercados de combustíveis. No entanto, estudos, como os de Salton e Mattos (2018) e Salvini, (2016), apontam para a existência de algum tipo de assimetria nos preços e discutem de forma diferente as possíveis causas dessa assimetria. Para o primeiro autor citado, a causa estaria relacionada à capacidade de armazenagem dos postos de combustíveis; já para o segundo, seriam os choques de demanda os causadores da assimetria.

No mercado varejista, os custos de se obter informação em relação à prática de preços pode levar a uma resposta assimétrica dos postos de combustíveis em relação às variações nos distribuidores. Esta situação demonstra que cada posto de combustível possui algum poder de mercado, local e limitado, decorrente da falta de informação do consumidor.

Todavia, o consumidor também pode provocar um efeito assimétrico ao mercado quando antecipa o consumo em resposta à informação de que os distribuidores de combustíveis "atacado" enfrentam um aumento dos custos e, possivelmente, um aumento dos preços. Com isso, elevam a demanda e, consequentemente, os preços. Esta hipótese foi discutida por Balke et al. (1998), sendo que o movimento causador da assimetria ocorreria do varejo para o atacado.

Considerando esses efeitos, este estudo tem como objetivo identificar a ocorrência de assimetria na transmissão de preços da gasolina para as maiores cidades do Rio Grande do Sul, contemplando o período entre janeiro de 2005 e dezembro de 2018. Adicionalmente, investigou-se a hipótese de transmissão assimétrica de preços do varejo para o atacado com base na estimação de cointegração entre os preços praticados pelos distribuidores (atacado) e pelos postos de combustíveis (varejo).

Para isso, utiliza-se um modelo de correção de erros (MCE) nas series de preços do varejo "postos de combustíveis" e nas series de preços do atacado "distribuidores". O MCE foi criado por Sargan (1964), no entanto foi popularizado, mais tarde, por Engle e Granger (1987), e sua origem adveio da necessidade de criar um modelo que considerasse a dinâmica de curto e longo prazo e o equilíbrio de maneira simultânea (CHEN, 2007). Dessa forma, trata-se de uma transformação linear simples, que integra ajustes de curto prazo juntamente com equilíbrio de longo prazo, sem perder informações de longo prazo. Engle \& Granger (1987) afirmam que o MCE é uma forma de conciliação entre o comportamento de curto e longo prazo de uma determinada variável econômica, e, ainda, a estimação do MCE é condição necessária para estimar um vetor de cointegração.

Assim, este artigo busca esclarecer como os postos de combustíveis poderiam influenciar os distribuidores em relação ao preço, sendo este seu diferencial, visto que a maioria dos estudos partem do pressuposto de que os postos de combustíveis sofrem influência dos distribuidores, tais como apontado por Meyer e Von Cramon-Taubadel (2004), Frey e Manera (2007), Salton e Mattos (2018) e Salvini, (2016). Dessa forma, busca-se identificar como a antecipação ao consumo da gasolina, diante da informação de que os preços no futuro aumentarão, vem a tornar a reação de reajuste dos preços prejudicial aos próprios agentes envolvidos. Destaca-se que uma das formas de controlar esse aumento na demanda seriam os postos reajustarem seus preços com mais frequência.

Dessa forma, justifica-se a escolha do tema proposto diante da existência de poucos estudos que analisam a estrutura de repasses de preços no mercado de combustíveis nacional e da necessidade de desenvolver pesquisas que visem analisar como os postos de combustíveis influenciam na determinação de preços na gasolina, estabelecidos pela distribuidora, e repassados ao consumidor final, verificando a existência de assimetria nestes.

Este artigo está dividido em outras cinco seções além dessa introdutória. A segunda traz a revisão de literatura; a terceira discute a estruturação do mercado brasileiro da gasolina; a quarta apresenta a metodologia, expondo o modelo e o conjunto de variáveis utilizadas; a seção seguinte, de resultados, analisa o comportamento do mercado de combustíveis no Rio Grande do Sul e a assimetria de preços dos combustíveis às cidades do estado do Rio Grande do Sul. E finaliza-se com as considerações finais a respeito do estudo realizado.

\section{REVISÃO DE LITERATURA}

Embora a existência de assimetria possa ser consistente com o poder de mercado, essa não é a única explicação que os economistas ofereceram para a resposta assimétrica dos preços da gasolina. De acordo com Balke et al. (1998), explicações alternativas incluem a resposta do consumidor à mudança de preços. Se os consumidores acelerarem suas compras de gasolina para superar aumento quando seu preço está subindo, eles aumentam os estoques em automóveis e acabam por elevar a demanda, contribuindo para o aumento do ritmo dos aumentos nos postos de combustíveis. Embora o autor tenha abordado essa temática, não conseguiu encontrar evidências para que as transmissões de preços da gasolina nos Estados Unidos, no período de 1987 a 1996, fossem assimétricas.

Já para o Brasil, o tema referente à transmissão dos preços da gasolina foi estudo por Silva et al. 
(2011), que, partindo de uma abordagem de cointegração com ajustamento threshold, realizaram uma análise para o conjunto de 131 cidades do Brasil, no período de 2004 a 2011. Os resultados colocam a região do nordeste com a maior em proporção de municípios que teriam um regime assimétrico de transmissão dos preços da gasolina quando comparado às demais regiões do Brasil. Uma das possíveis justificativas para esses resultados está no fato de apresentar possíveis falhas de mercado, como a formação de cartéis.

Outro trabalho que compartilha da hipótese da presença de falhas de mercado é o realizado por Canêdo-Pinheiro (2011) que, para o período de 1999 a 2010, analisou a transmissão dos preços do óleo diesel no atacado para os consumidores finais no Brasil, por meio de um Modelo de Correção de Erros, obtendo resultados que apontaram para a assimetria de curto e longo prazo, a qual leva a uma transferência de $\mathrm{R} \$ 2,1$ bilhões por ano dos consumidores para os distribuidores em decorrência dessa assimetria.

A abordagem feita por Salvini (2016) resultou na identificação, pelo modelo de correção de erros, da transmissão assimétrica de preços no curto prazo para o mercado do etanol e para o mercado da gasolina no estado de são Paulo, para o período de 2002 a 2013. Esses resultados evidenciam que as variações do preço nos distribuidores não são repassadas de forma igual pelos postos de combustíveis. Entretanto, esse mercado não constatou a existência de transmissão assimétrica dos preços para o longo prazo.

Ainda de acordo com Salvini (2016), um possível fato gerador de assimetria de curto prazo é a percepção dos consumidores de que qualquer informação relacionada ao aumento de preços, no mercado nacional de combustíveis, leva a uma antecipação do consumo como forma de proteção frente às variações dos preços nos postos de combustíveis. Contudo, essa expansão do nível do consumo leva ao esgotamento dos estoques, obrigando os proprietários de postos a elevar o preço do combustível como meio de conter a demanda.

Em um estudo mais recente, Salton e Mattos (2018) buscaram entender como se dá a transmissão de preços para o mercado do etanol nas cidades brasileiras, considerando o período de 2004 a 2017. Os autores buscaram identificar a presença de assimetria tanto do varejo para o atacado (Upstream), como do atacado para o varejo (Downstream), utilizando o modelo de correção de erros. Os resultados evidenciaram repasses assimétricos em uma proporção de $9,2 \%$ das cidades analisadas para o Upstream e $36,7 \%$ das cidades analisadas para o Downstream.

Ainda, para Salton e Mattos (2018), a presença da assimetria seria justificada por meio da presença de efeitos de escala dos postos de combustíveis, dado que a compra realizada pelos postos de combustíveis junto aos distribuidores, para a renovação de seus estoques, ocorreria em momentos de preços mais baixos nos distribuidores, de forma que isso não seria repassada pelos postos de combustíveis ao consumidor final, o que potencializaria a margem de lucro dos postos de combustíveis.

Em estudo realizado para os repasses dos preços da gasolina nos postos de combustíveis do Brasil, que tinha por objetivo verificar se a assimetria é característica das firmas ou do mercado de combustíveis, Cardoso et al. (2016), utilizando do Modelo de Correção de Erro Assimétrico, chegaram a resultados que $71 \%$ dos postos não responde assimetricamente, enquanto que dos que respondem assimetricamente, $23 \%$ responde com uma assimetria positiva e 6\% com assimetria negativa. Os autores concluem que postos com maiores margens e com bandeira diferente da branca possuem maior probabilidade de ter assimetria positiva, assim como o fato de a escassez de concorrentes próximos ser um dos motivos da presença de assimetria.

Em análise realizada pela Agência Nacional do Petróleo (2019), agência responsável pela edição de normas e regulamentação dos mercados de combustíveis no Brasil, foi constatado que, no período de 2017 a 2018, reajustes praticados pelos produtores de gasolina são acompanhados pelos distribuidores, mas em intensidades diferentes e com uma defasagem temporal, fornecendo evidencias de que os repasses nos preços são acometidos pelo fenômeno da assimetria, porém, à agencia ressalta que a análise pode ser objeto de maior aprofundamento, com a utilização de ferramental estatístico e econométrico.

Percebe-se, assim, a utilização de distintas metodologias na avaliação da transmissão de preços em diferentes mercados. De maneira ampla, os estudos recentes feitos no Brasil encontraram evidências para a assimetria de preços nos mercados total ou parcial. Considerando que o objetivo está em testar a hipótese do consumidor de que os preços não se ajustam de forma simétrica, os resultados levam à confirmação desta hipótese.

\section{ESTRUTURAÇÃO DO MERCADO BRASILEIRO DA GASOLINA}

A gasolina tem, em sua composição, a mistura da gasolina "A", que é a gasolina de origem das refinarias da Petróleo Brasileiro S. A. (Petrobras). Com o etanol anidro, gera a mistura denominada gasolina "C", cujo percentual a ser adicionado de álcool anidro à gasolina "A" pode variar de $18 \%$ a $27 \%$ segundo a Agência Nacional do Petróleo, Gás Natural e Biocombustíveis (ANP, 2018a). A justificativa da utilização de aditivos atualmente se refere à agregação de benefícios à gasolina como melhoria na combustão, melhora no desempenho do motor e limpeza de bicos injetores ou válvulas.

No ano de 2017, segundo o ANP (2018a), o percentual do petróleo destinado à produção da gasolina 
"A" estava em torno de $28,7 \%$, ficando com a segunda colocação entre os derivados do petróleo, somente atrás do óleo diesel, que estava em torno de $42 \%$ da produção total de derivados energéticos de petróleo. Em termos de produção, a gasolina "A" teve a produção de aproximadamente 25,06 milhões de metros cúbicos em 2018, originárias de 14 refinarias, distribuídas em oito estados do Brasil.

Quando se avalia a evolução da quantidade de gasolina produzida no Brasil, verifica-se um comportamento crescente, no período de 2008 até 2014, atingindo 30 milhões de metros cúbicos nesse último ano; porém, nos anos mais recentes, essa trajetória inverteu-se, com redução na quantidade produzida, ficando em torno dos 25 milhões de metros cúbicos produzidos de gasolina em 2014, patamar semelhante ao produzindo em 2011 (Figura 1). Esta diminuição é reflexo do estágio de paralisia da economia que se reflete em diminuição do poder de compra dos consumidores, diminuindo a demanda por gasolina, conforme CBIE (2019)

Figura 1 - Produção de gasolina no Brasil, entre 2008 e 2018, em milhões de metros cúbicos.

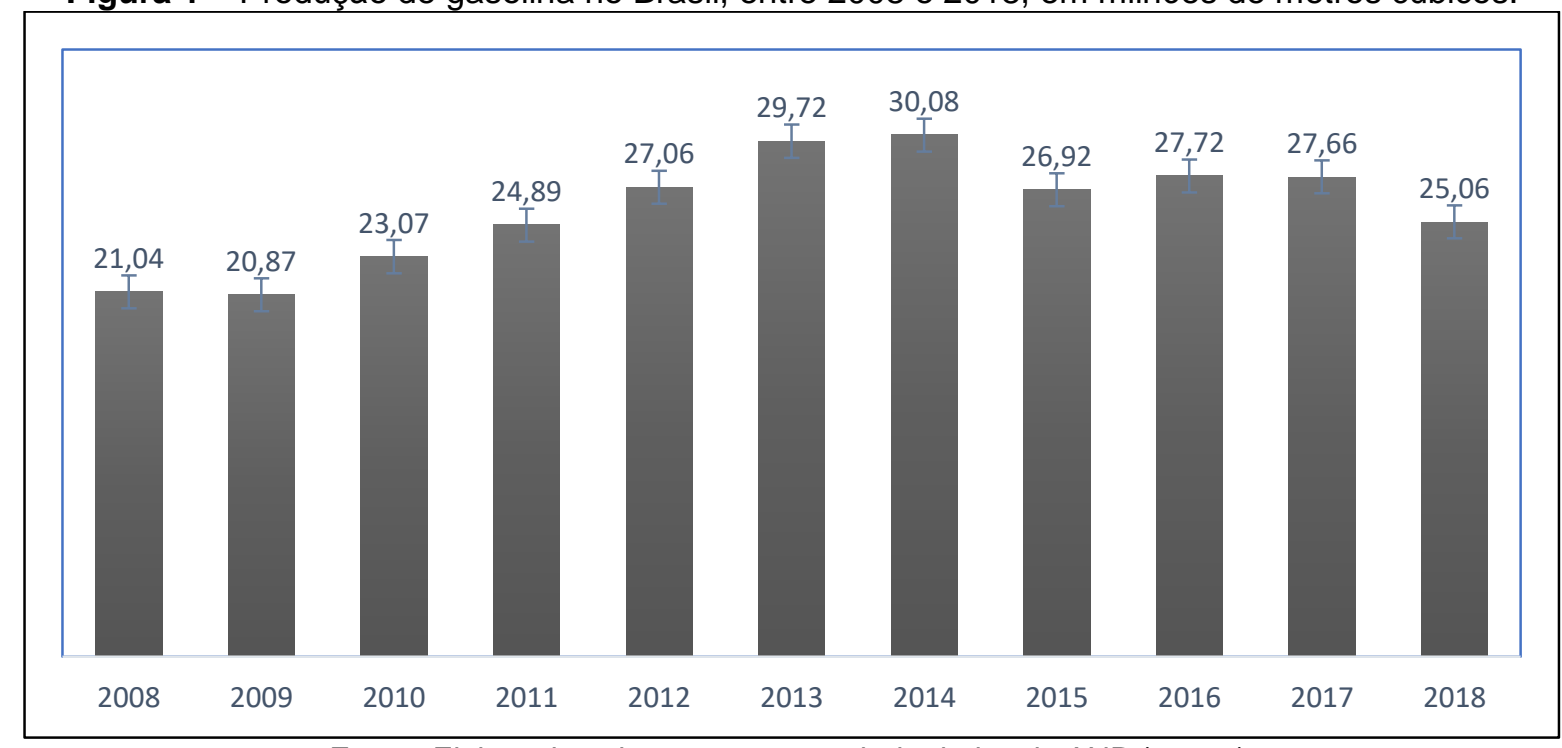

Fonte: Elaborada pelos autores a partir de dados da ANP (2019a).

Quanto à política de preços, a metodologia de precificação dos combustíveis, até junho de 2017, apresentava um repasse dos preços internacionais menos flexível, levando a Petrobras a arcar com prejuízos relativos à variação dos preços do petróleo no mercado internacional. Posterior a junho de 2017, a Petrobras anunciou mudança na metodologia para a formação de preços, com os reajustes ocorrendo em um menor espaço de tempo e dependendo das oscilações do petróleo no mercado externo. Com esta mudança de política, a Petrobras prevê reduções de prejuízos com as variações do petróleo no mercado externo, como também projeta a convergência dos preços dos combustíveis praticados no Brasil e no mercado externo (PETROBRAS, 2019). Porém, os parâmetros metodológicos do cálculo do reajuste dos preços ficam restritos à companhia por razões comerciais.

A distribuição de gasolina, no Brasil, é feita por 131 distribuidoras, porém, ao mesmo tempo em que se tem uma expressiva quantidade de empresas ligadas ao ramo de distribuição, há, também, uma elevada concentração de mercado entre as três maiores, sendo elas: a transportadora BR, que possui maior fatia de mercado, sendo responsável pela distribuição de $24 \%$ das vendas nacionais, seguida pela distribuidora Ipiranga que é responsável pela distribuição de, aproximadamente, $20 \%$ das vendas nacionais e pela Raízen que tem uma participação no mercado de distribuição de aproximadamente $17 \%$ das vendas nacionais (ANP, 2019).

Conjuntamente, estas três empresas concentram fatia de mercado superior a $60 \%$ da distribuição total dos combustíveis para o Brasil, enquanto as outras 128 distribuidoras ficam com o restante do mercado, correspondente a 39\% da distribuição total de acordo com ANP (2018a). Esta alta concentração se deve, de forma importante, ao custo elevado relacionado à logística, aspecto que faz com que empresas maiores mantenham importante parte da distribuição do mercado. A Figura 2 apresenta a participação das distribuidoras de gasolina C no mercado brasileiro para o ano de 2018. 
Figura 2 - Participação das distribuidoras nas vendas nacionais de gasolina C em 2018.

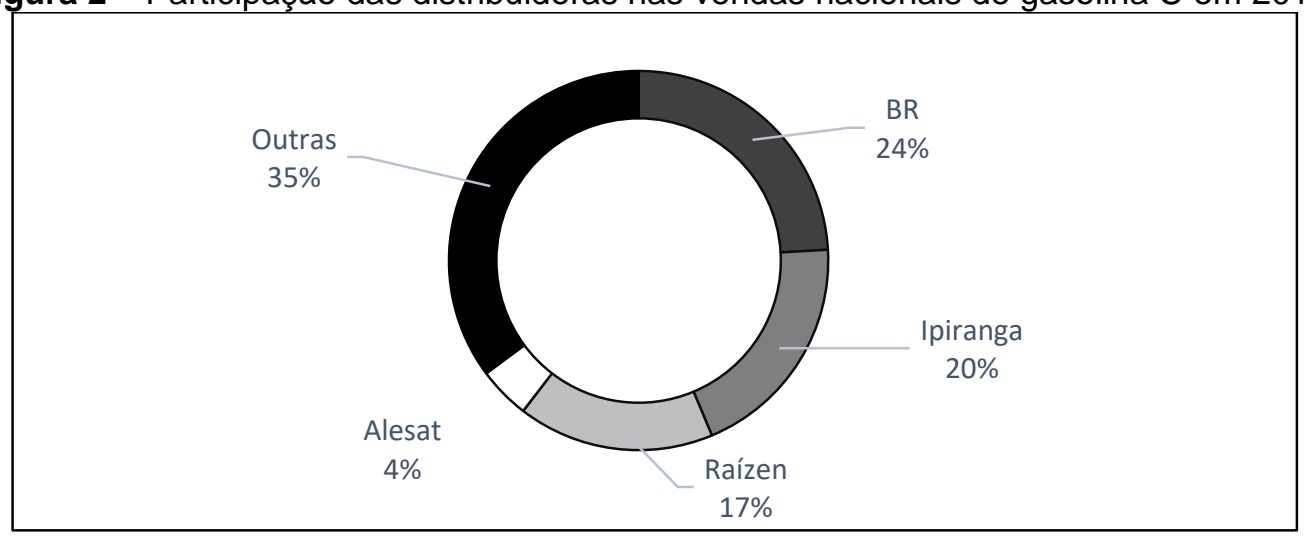

Fonte: Elaborada pelos autores a partir de dados da ANP (2019).

Em termos de consumo de gasolina, verifica-se que, no Rio Grande do Sul, no período de 2005 até 2014, a gasolina apresentou crescimento (Figura 3), acompanhando a economia brasileira que se encontrava em expansão, com aumento de renda e possibilitando aos consumidores aumento do consumo segundo a ANP (2018a). Entretanto, depois de 2014, a economia passou a apresentar sinais de redução do crescimento, com consequentes reflexos na renda. Como consequência, observa-se estabilização no consumo de gasolina.

Figura 3 - Consumo de gasolina para o Rio Grande do Sul para o período 2005-2017, em bilhões de litros.

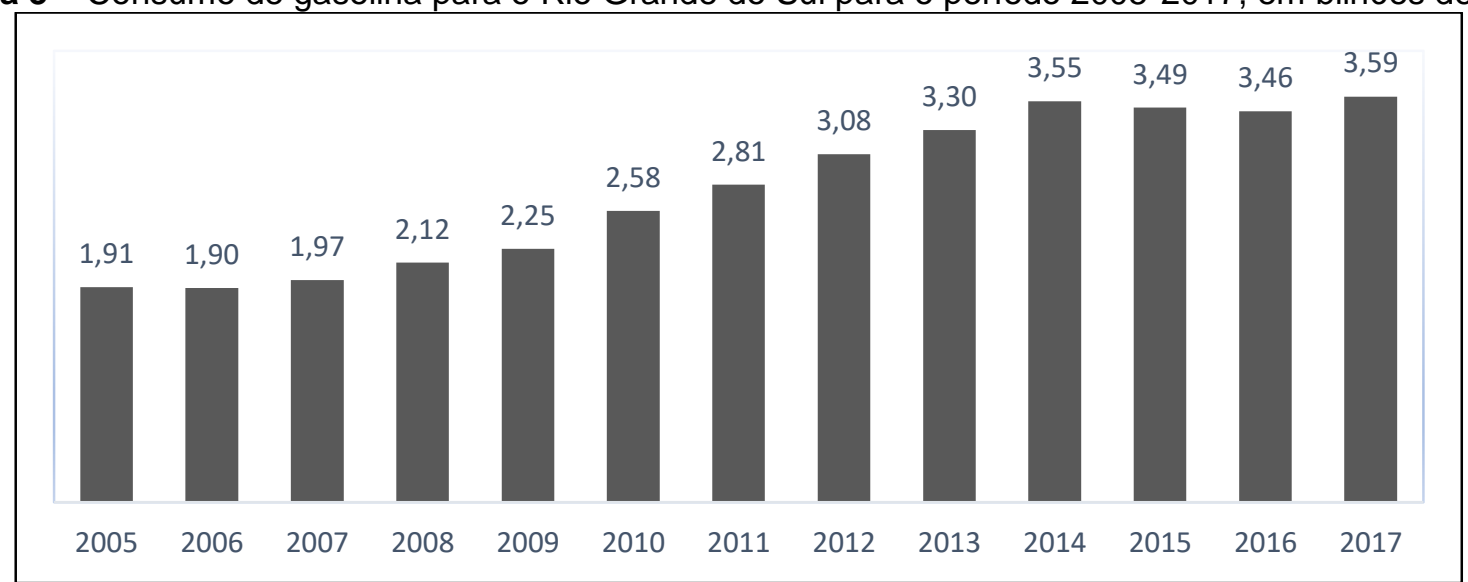

Fonte: Elaborada pelos autores a partir de dados da ANP (2019a).

Estes fatores possibilitam compreender que a dinâmica do mercado brasileiro de gasolina está relacionada à distribuição altamente concentrada e à sensibilidade do consumo a variações na renda combinado com o aumento da frota de veículos flex fuel, que possibilita a substituição da gasolina pelo álcool, levam a conclusões de que a gasolina tem características de consumo elástico, e essa condição é o que determina que, em períodos de recessão econômica, a demanda tende a retrair de forma expressiva conforme apontado por Anna e Bastos (2014).

\section{METODOLOGIA}

Com a estratégia metodológica, pretende-se verificar se ocorrem transmissões assimétricas do varejo para o atacado (upstream) nas maiores cidades do Rio Grande do Sul. O modelo utilizado, conforme equação em (1), segue a estrutura apresentada por Frey e Manera (2005). Esse modelo avalia se a transmissão ocorre de forma assimétrica do varejo, que é representado pelos postos de combustíveis, para os atacadistas, os quais são representados pelos distribuidores de combustíveis.

$$
\Delta P_{i, t}^{A}=\beta_{h} \Delta P_{i, t-1}^{A}+\sum_{l=0}^{l+} \alpha_{l}^{+} \Delta P_{i, t-j}^{V}+\sum_{l=0}^{l-} \alpha_{l}^{-} \Delta P_{i, t-j}^{V-}+\lambda^{+} E C T_{t-j}^{+}+\lambda^{-} E C T_{t-j}^{-}+\mu_{i, t}, \forall i
$$

As definições e as descrições das variáveis encontram-se expostas no Quadro 1. 
Quadro 1 - Descrição das variáveis do modelo.

\begin{tabular}{|c|c|}
\hline Variável & Descrição \\
\hline$\Delta P_{i, t}^{A}$ & Representa a diferença da variável preço praticado no atacado. \\
\hline$\Delta P_{i, t-1}^{A}$ & Representa um termo defasado da diferença do preço praticado no atacado. \\
\hline$\Delta P_{i, t-j}^{V}$ & $\begin{array}{r}\text { É um vetor construído a partir da aplicação da diferença do preço do varejo, em } \\
\text { que os valores positivos são conservados, e os valores negativos são } \\
\text { substituídos pelo número zero. }\end{array}$ \\
\hline$\Delta P_{i, t-j}^{V-}$ & $\begin{array}{r}\text { É um vetor construído a partir da aplicação da diferença do preço do varejo, em } \\
\text { que os valores negativos são conservados, e os valores positivos são } \\
\text { substituídos pelo número zero. }\end{array}$ \\
\hline$E C T_{t-j}^{+}$ & $\begin{array}{r}E \text { um vetor construído com a equação (3), em que se conservam os valores } \\
\text { positivos, e os valores negativos são substituídos pelo número zero. }\end{array}$ \\
\hline$E C T_{t-j}^{-}$ & $\begin{array}{c}\text { É um vetor construído com a equação (3), em que se conservam os valores } \\
\text { negativos, e os valores positivos são substituídos pelo número zero. }\end{array}$ \\
\hline
\end{tabular}

Fonte: elaboração dos autores.

Para a construção dos vetores ECTs incluídos na equação (1), é, inicialmente, estimada a regressão exposta em (2).

$$
P_{t}^{A}=\beta_{1}+\beta_{2} P_{t}^{V}+\mu_{t}
$$

em que $P_{t}^{V}$ representa o preço da gasolina no varejo no tempo te $P_{t}^{A}$ o preço da gasolina no atacado no tempo $t ; \beta_{1}$ e $\beta_{2}$ os parâmetros estimados e $\mu_{t}$ é o termo de erro que assume média zero e variância $\sigma^{2}$.

A partir dessa estimação, são obtidos os resíduos conforme formulação em (3).

$$
\mu_{t}=P_{t}^{A}-\beta_{1}-\beta_{2} P_{t}^{V}
$$

Logo, as variáveis $E C T_{t-j}^{+}$e $E C T_{t-j}^{-}$resultam da diferenciação dos resultados da série de resíduos, os quais são posteriormente separados em dois vetores. Para o $E C T_{t-j}^{+}$mantêm-se as variações positivas, e as variações negativas são substituídas por zero, enquanto que, para o $E C T_{t-j}^{-}$são conservadas as variações negativas, e as variações positivas são substituídas igualmente por zero.

Todavia, para avaliar se há presença de transmissão assimétrica, utiliza-se o teste $F$, sendo avaliada a hipótese nula relacionada aos coeficientes estimados para as diferenças no atacado e no varejo expressas por:

$H_{0}: \alpha_{l}^{+}=\alpha_{l}^{-}$permite verificar a existência de assimetria no curto prazo, em que a hipótese nula, de igualdade dos parâmetros, confirma que os repasses de preços da gasolina, no atacado, respondem da mesma forma que as variações positivas ou negativas dos preços no varejo "repasses simétricos de preços no curto prazo".

$H_{0}: \lambda^{+}=\lambda^{-}$permite verificar a existência de assimetria no longo prazo, em que a hipótese nula, de igualdade dos parâmetros, confirma que os repasses de preços da gasolina no atacado respondem de mesma forma que as variações positivas ou negativas dos preços no varejo num período mais longo "repasses simétricos de preços no longo prazo".

Para a realização do mecanismo de correção de erros, faz-se necessária a utilização de testes para que as séries atendam a certos pressupostos. Nesse sentido, a realização de testes de quebra estrutural tem grande importância, de acordo com Maddala e Kim (1998), pois a presença de quebra estrutural pode gerar viés nos testes de cointegração, assim como os testes de raiz unitária perdem poder de análise.

Para esta finalidade, utilizou o teste de quebra estrutural múltipla, cujo objetivo é verificar se os coeficientes apresentam estabilidade ao decorrer do tempo. Ele se baseia na aplicação do teste $t$ de HarveyCollier que tem como hipótese nula a estabilidade dos parâmetros, resultado que aponta para um processo sem quebras estruturais (GREENE, 2003). De outro lado, a presença de uma quebra estrutural na série torna inviável a estimação de um modelo que enumere resultados com confiabilidade, portanto a detecção de quebra estrutural da série leva à exclusão da cidade às análises.

$\mathrm{Na}$ etapa seguinte, verificou-se a ordem de integração das séries de preços da gasolina no varejo e no atacado. Para a confirmação de cointegração de Engle-Granger, é necessário que as séries sejam não estacionárias (ou possuam raiz unitária) em nível para que possa haver relação de longo prazo, como também faz-se necessário que as séries apresentem mesma ordem de integração. Posteriormente, estima-se uma regressão entre as respectivas variáveis, sendo que delas obtêm-se os resíduos, e aplica-se o teste Dickey- 
Fuller Aumentado; caso os resíduos sejam estacionários, conclui-se pela evidência de cointegração, conforme Engle e Granger (1987).

Assim sendo, como se torna inviável a aplicação do mecanismo de correção de erros para o caso de as variáveis não apresentarem cointegração, são excluídas da análise as cidades em que não apresentarem relacionamento estatístico de longo prazo.

Dados estes pressupostos, as séries que apresentarem estacionariedade em nível ou ordens diferentes são também descartadas da análise. Para verificar a estacionariedade das séries, foram aplicados os testes de raiz unitária de Phillips-Perron e de KPSS, ambos aplicados com e sem tendência determinística linear.

O primeiro tem como hipótese nula que o processo possui raiz unitária "processo não é estacionário". Esse teste possui vantagem em relação aos demais pelo fato de fazer uma correção não paramétrica na estatística $t$, transformando o teste robusto para autocorrelação não especificada e a heterocedasticidade no processo de perturbação da equação do teste, de acordo com Russell e MacKinnon (2004).

Já o segundo apresenta a hipótese nula diferente dos demais, em que tem o propósito de testar a variância. Ele tem, na hipótese nula, a condição de que a variância é nula, implicando um processo estacionário. Complementando, de acordo com Vatto (2014), este teste tem maior poder que os demais quando são tratados em questão às séries que apresentam quebras estruturais.

Considerando os possíveis problemas de estimação, são aplicados testes de diagnóstico. Para verificar a heterocedasticidade, aplicou-se o teste Breusch-Pagan-Godfrey, cuja hipótese nula evidencia a igualdade de variâncias e, para a presença de autocorrelação, aplicou-se o teste de Ljung-Box, cuja hipótese nula é ausência de correlação serial. Em caso de evidência desses problemas, fez-se uso da inferência robusta de Newey-West, que propõe um estimador geral da matriz variância-covariância dos estimadores dos coeficientes dos regressores, como sendo consistente mesmo com a presença de autocorrelação e heterocedasticidade com padrões desconhecidos, conforme proposto por Greene (2003).

Finalizando, quanto aos dados referentes à comercialização da gasolina para o estado do Rio Grande do Sul, estes foram obtidos juntos ao sítio da ANP (2019b), sendo coletados os preços praticados pelos distribuidores de gasolina, denominados de preço de atacado e, pelos postos de gasolina, denominada de preço do varejo; também, foi coletada a margem de comercialização por parte do varejista denominada de margem.

Os dados compreendem o período de janeiro de 2005 a dezembro de 2018, com uma frequência mensal, extensão temporal que totalizou 168 observações. Os dados foram coletados a termos nominais, individualmente para cada uma das cidades analisadas. Ainda, as variáveis coletadas em relação ao preço da gasolina estão mensuradas em $\mathrm{R} \$$ /litro.

Quanto às unidades de análise, foram coletados os dados referentes àquelas cidades do estado do Rio Grande do Sul que apresentaram população igual ou superior a 100.000 habitantes, segundo a Fundação de Economia e Estatística FEE (2019), limite que restringiu a amostra a 20 cidades ${ }^{1}$. Essa restrição foi imposta dada a indisponibilidade de dados para cidades menores a essa população, apresentando uma grande falta de observações nas séries coletadas, o que apresentaria viés nos resultados estimados por meio do modelo.

\section{RESULTADOS}

\subsection{O Mercado de Gasolina no Rio Grande do Sul}

Os preços médios da gasolina no varejo e no atacado e a margem de comercialização nas cidades do estado do Rio Grande do Sul encontram-se na Tabela 1. Observa-se que os preços no varejo apresentam valores médios mais elevados que os do atacado, enquanto o preço médio do varejo ficou em torno de $R \$ 3,09$, o preço no atacado apresentou média em torno $R \$ 2,66$; por sua vez, a margem de comercialização ficou em média $\mathrm{R} \$ 0,42$, o que representa $13,66 \%$ do preço praticado aos consumidores pelos varejistas.

Tabela 1 - Estatísticas descritivas dos preços das cidades analisadas

\begin{tabular}{lcccc}
\hline \multicolumn{1}{c}{ Variáveis } & Média & Desvio Padrão & Mínimo & Máximo \\
\hline Preço Varejo & $\mathrm{R} \$ 3,09$ & 0,5996 & $\mathrm{R} \$ 2,47$ & $\mathrm{R} \$ 4,85$ \\
Preço Atacado & $\mathrm{R} \$ 2,66$ & 0,5591 & $\mathrm{R} \$ 2,11$ & $\mathrm{R} \$ 4,35$ \\
Margem & $\mathrm{R} \$ 0,42$ & 0,0534 & $\mathrm{R} \$ 0,34$ & $\mathrm{R} \$ 0,57$ \\
\hline
\end{tabular}

Fonte: Elaboração própria com base nos dados da ANP (2019).

\footnotetext{
${ }^{1}$ São as cidades de Porto Alegre, Caxias do Sul, Canoas, Pelotas, Santa Maria, Gravataí, Viamão, Novo Hamburgo, São Leopoldo, Rio Grande, Alvorada, Passo Fundo, Sapucaia do Sul, Cachoeirinha, Santa Cruz do Sul, Uruguaiana, Bagé, Bento Gonçalves, Erechim e Guaíba.
} 
Em relação à margem de comercialização, o valor mínimo que os postos de combustíveis recebem por litro de gasolina está em torno de $R \$ 0,34$, enquanto que o máximo está em torno de $R \$ 0,57$. Esta variabilidade aponta que os postos tendem a não assumir prejuízos (ou redução da margem) em decorrência de alterações nos preços nos distribuidores, transmitindo a elevação dos custos para o consumidor final.

Em termos de evolução, conforme Figura 4, a margem apresentou comportamento volátil, com variações importantes principalmente após 2015. Já com relação às séries de preços do atacado e do varejo, observa-se certa estabilidade dos preços, no período de 2005 a 2014. Porém, a partir de 2015, a série de preços apresenta tendência de elevação coincidente com o período de aumento da volatilidade da margem. Esta mudança reflete a nova política de preços da Petrobras, na qual os preços buscam uma maior paridade diante das variações no mercado internacional, com isso se aumenta a volatilidade dos preços no mercado nacional, de acordo com ANP (2019a). Ainda, observa-se que as variações positivas nos preços do atacado são repassadas de forma instantânea pelos varejistas com um reajuste maior que o ocorrido no varejo, isso se torna sugestivo com a visualização da margem de comercialização. Também, a margem apresenta elevação na maioria dos casos em que ocorrem variações negativas nos preços do atacado, evidenciando que as variações nos preços no curto prazo refletem em aumento dos lucros por parte dos postos de combustíveis.

Figura 4 - Evolução das variáveis de preços da gasolina no atacado e no varejo e da margem, entre 2005 e 2018, em R\$.

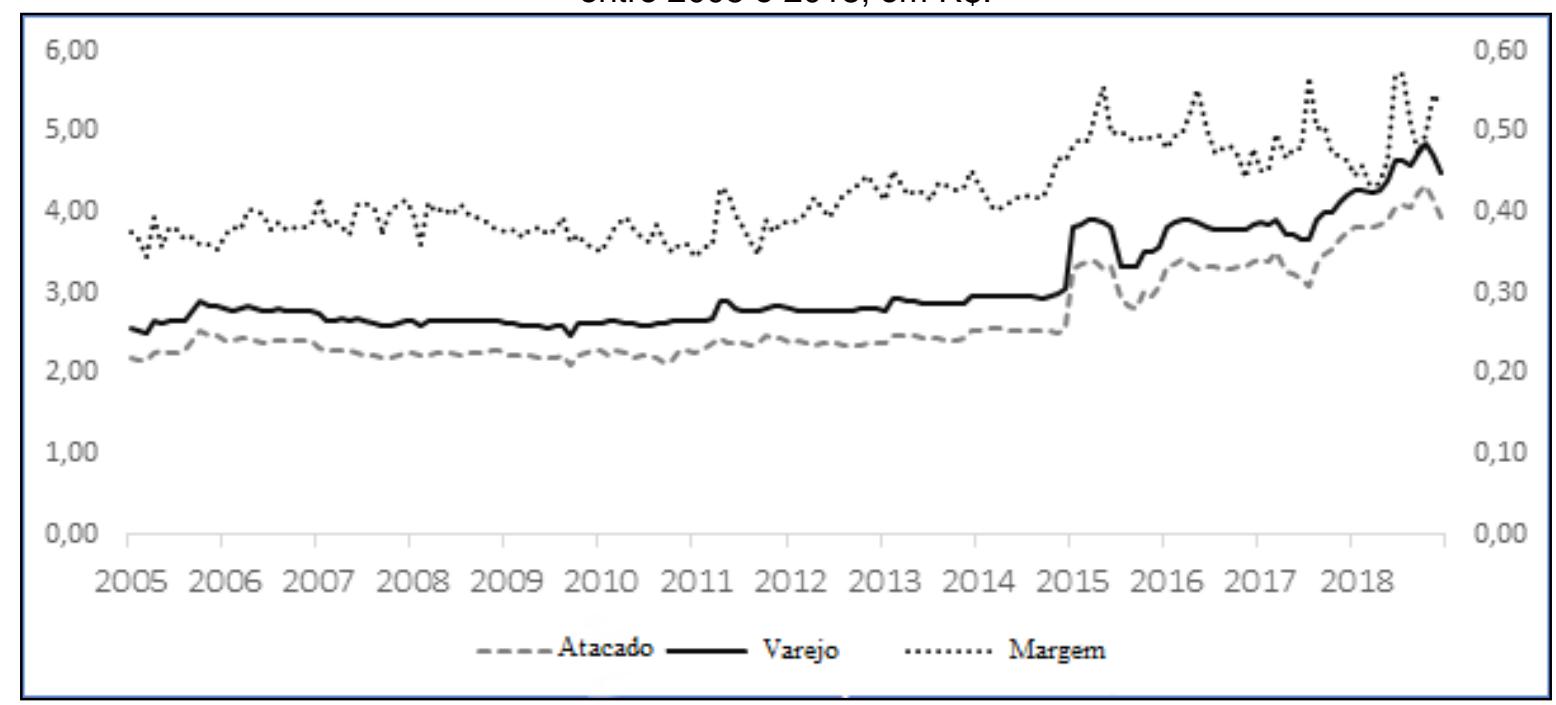

Fonte: Elaborada pelos autores a partir de dados da ANP (2019).

Nota: no eixo primário, estão relacionadas as séries de preços do atacado e do varejo, enquanto, para o eixo secundário, está relacionado á margem de comercialização.

Complementando, analisa-se a evolução das séries em primeira diferença (Figura 5). As maiores oscilações ocorrem no período posterior a 2015 , período em que se destacam as variações positivas, as quais ocorrem em maior quantidade do que as variações negativas. Confirmando a evidência de que os choques nos preços no atacado se transferem quase que de forma integral ao varejo. 
Figura 5 - Variação do nível dos preços da gasolina no atacado e no varejo, no Rio Grande do Sul, entre 2005 e 2018.

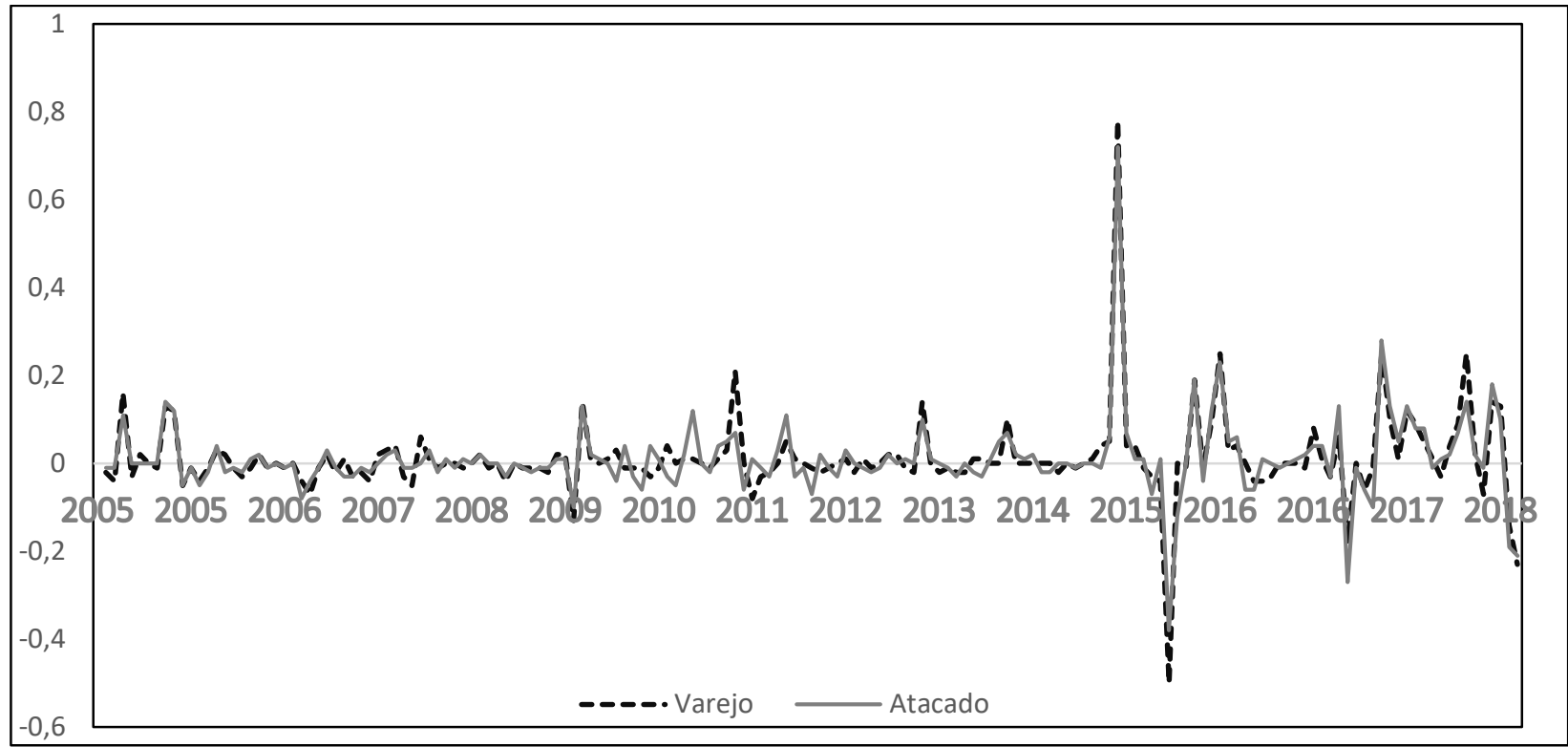

Fonte: Elaborada pelos autores a partir de dados da ANP (2019).

Essa dinâmica sugere que as séries de preços da gasolina no varejo e no atacado, no estado do Rio Grande do Sul, apresentam comportamentos de ajustes que, na maioria das vezes, ocorrem no mesmo sentido da variação apresentada. Observação essa que favorece a evidência de que as séries de preços do atacado e do varejo tendem a apresentar comportamento comum no longo prazo.

\subsection{Análise da assimetria de preços dos combustíveis às cidades do estado do Rio Grande do Sul}

O processo de validação do modelo inicia-se com a aplicação do teste de quebra estrutural e dos testes de raiz unitária, seguidos dos testes do cointegração Engle-Granger. Ainda, foram realizados testes de diagnóstico com a finalidade de verificar se há a presença de autocorrelação e heterocedasticidade. Após essas definições, foram estimados os modelos para verificar a presença ou não de assimetria na transmissão de preços no mercado da gasolina nas maiores cidades do Rio Grande do Sul.

O teste de quebra estrutural múltipla tem o objetivo de verificar se os coeficientes são estáveis ao longo do tempo. A presença de quebra estrutural leva a um viés na aplicação dos testes de cointegração e dos testes de raiz unitária conforme discutem Maddala e Kim (1998). Seguindo este argumento, aplicou-se o teste $t$ de Harvey-Collier, cujo resultado utiliza o nível de confiança a 1\%, em que o coeficiente, sendo significativo, confirma a presença de quebra estrutural. De forma geral, as séries não apresentaram quebras estruturais; a exceção é feita à série de preço no atacado à cidade de Bento Gonçalves (Tabela 2). Resultado que determinou a exclusão dessa unidade para a sequência da análise, sendo incluídas as séries das cidades que não apresentaram quebra estrutural.

Tabela 2- Resultados do teste de quebra estrutural múltipla de preços às cidades analisadas

\begin{tabular}{lcc}
\hline \multicolumn{1}{c}{ Cidades } & Preço no varejo & Preço no atacado \\
\hline Alvorada & $0,9538^{* *}$ & $0,8565^{*}$ \\
Bagé & 0,4527 & 0,8060 \\
Bento Gonçalves & 0,5921 & $1,2641^{* * *}$ \\
Cachoeirinha & $0,9588^{\star *}$ & 0,6423 \\
Canoas & $0,9333^{* *}$ & 0,6764 \\
Caxias do Sul & 0,4275 & 0,4715 \\
Erechim & 0,6282 & 0,5627 \\
Gravataí & $0,8585^{\star}$ & $0,9766^{\star *}$ \\
Guaíba & 0,6851 & $1,0435^{\star *}$ \\
Novo Hamburgo & $1,0955^{\star *}$ & 0,7284 \\
Passo Fundo & 0,5238 & 0,8367
\end{tabular}




\begin{tabular}{lcc}
\hline \multicolumn{1}{c}{ Cidades } & Preço no varejo & Preço no atacado \\
\hline Pelotas & 0,3981 & 0,4516 \\
Porto Alegre & 0,8425 & 0,5524 \\
Rio Grande & 0,5291 & $1,0216^{* *}$ \\
Santa Cruz do Sul & 0,6767 & 0,5925 \\
Santa Maria & 0,6198 & 0,5587 \\
São Leopoldo & $0,9882^{\star *}$ & 0,7195 \\
Sapucaia do Sul & $0,9614^{* *}$ & 0,7313 \\
Uruguaiana & 0,5351 & 0,6806 \\
Viamão & 0,6930 & 0,6297 \\
\hline
\end{tabular}

Fonte: Resultados da pesquisa (2020).

Nota: o teste de quebra estrutural Harvey-Collier tem como hipótese nula a ausência (não presença) de quebra estrutural, enquanto a hipótese alternativa aponta a presença de quebra estrutural. Os valores críticos para o teste são: $1 \%$ de significância $1,1430,5 \%$ de significância 0,9479 e $10 \%$ de significância $0,850 .{ }^{* * *}$, ** $e^{*}$ indicam a rejeição da hipótese nula a $1 \%, 5 \%$ e $10 \%$, respectivamente.

Seguindo, para avaliar a estacionariedade das séries, foram empregados dois testes, sendo eles: Phillips-Perron e KPSS. Ambos foram estimados com e sem a inclusão de tendência determinística. Como se trata de duas séries para cada cidade, os resultados foram separados nas Tabelas 3 e 4, com os resultados dos testes de raiz unitária referente aos preços praticados no varejo e no atacado, respectivamente.

Os resultados indicam que a variável preço no varejo em nível, para todas a cidades, apontou a presença de raiz unitária por ambos os testes, tanto com a inclusão da tendência determinística, como sem ela. Porém, com a aplicação da primeira diferença, em ambos os testes de verificação de presença de raiz unitária, observa-se que a variável se torna estacionária. Assim, conclui-se que a variável preço no varejo possui ordem de integração um I(1).

Tabela 3 - Resultados dos testes de raiz unitária para as séries de preço no varejo

\begin{tabular}{|c|c|c|c|c|c|c|}
\hline \multirow{2}{*}{ Cidades } & \multicolumn{4}{|c|}{ Em nível } & \multicolumn{2}{|c|}{ Em primeira diferença } \\
\hline & $P P$ & PP+trend & KPSS & KPSS+trend & $P P$ & KPSS \\
\hline Alvorada & $-0,216$ & $-2,158$ & $6,52^{\star \star \star}$ & $1,57^{* \star *}$ & $-13,499^{* * *}$ & 0,132 \\
\hline Bagé & 0,249 & $-1,524$ & $6,62^{\star \star \star}$ & $1,81^{* * *}$ & $-11,725^{\star \star \star}$ & 0,222 \\
\hline Cachoeirinha & $-0,263$ & $-2,197$ & $6,49^{\star \star \star}$ & $1,6^{\star *}$ & $-13,836^{* * *}$ & 0,124 \\
\hline Canoas & $-0,216$ & $-1,96$ & $6,19^{\star \star *}$ & $1,61^{* * *}$ & $-12,478^{\star * *}$ & 0,154 \\
\hline Caxias do Sul & 0,134 & $-1,67$ & $6,54^{\star \star \star}$ & $1,63^{* \star *}$ & $-11,995^{\star \star \star}$ & 0,197 \\
\hline Erechim & $-0,368$ & $-2,072$ & $6,6^{* * *}$ & $1,62^{* * *}$ & $-11,206^{\star * *}$ & 0,122 \\
\hline Gravataí & $-1,995$ & $-2,084$ & $6,38^{* \star *}$ & $1,61^{\star * *}$ & $-12,121^{\text {***}}$ & 0,149 \\
\hline Guaíba & $-0,022$ & $-1,964$ & $6,48^{\star \star \star}$ & $1,49^{\star \star \star}$ & $-11,870^{\star * *}$ & 0,178 \\
\hline Novo Hamburgo & $-0,597$ & $-2,327$ & $6,18^{\star \star \star}$ & $1,43^{\star \star *}$ & $-11,427^{\star \star \star}$ & 0,109 \\
\hline Passo Fundo & $-0,164$ & $-1,971$ & $6,7^{* * *}$ & $1,62^{* \star *}$ & $-11,133^{\star * *}$ & 0,154 \\
\hline Pelotas & $-0,179$ & $-1,915$ & $6,54^{\star \star \star}$ & $1,65^{\star \star \star}$ & $-11,079^{\star \star \star}$ & 0,159 \\
\hline Porto Alegre & $-0,147$ & $-1,99$ & $6,41^{* * *}$ & $1,63^{\star * *}$ & $-12,524^{\star * *}$ & 0,156 \\
\hline Rio Grande & $-0,227$ & $-1,952$ & $6,54^{\star \star \star}$ & $1,67^{\star \star \star}$ & $-11,495^{\star \star \star}$ & 0,145 \\
\hline Santa Cruz do Sul & 0,026 & $-1,867$ & $6,56^{\star \star \star}$ & $1,62^{\star \star \star}$ & $-13,323^{\star \star *}$ & 0,164 \\
\hline Santa Maria & $-0,082$ & $-1,88$ & $6,53^{\star \star \star}$ & $1,61^{\star \star \star}$ & $-11,317^{\star \star \star}$ & 0,164 \\
\hline São Leopoldo & $-0,397$ & $-2,104$ & $6,29^{\star \star \star}$ & $1,53^{\star \star \star}$ & $-12,177^{\star * *}$ & 0,12 \\
\hline Sapucaia do Sul & $-0,422$ & $-2,219$ & $6,41^{\star \star \star}$ & $1,53^{\star \star *}$ & $-11,450^{\star \star \star}$ & 0,123 \\
\hline Uruguaiana & $-0,128$ & $-1,75$ & $6,54^{\star \star *}$ & $1,73^{\star * *}$ & $-11,211^{\text {***}}$ & 0,155 \\
\hline Viamão & $-0,046$ & $-1,888$ & $6,44^{\star \star \star}$ & $1,61^{* * *}$ & $-11,668^{\star * *}$ & 0,179 \\
\hline
\end{tabular}

Fonte: Resultados da pesquisa (2020).

Nota: A hipótese nula a ser testada pelo Phillips-Perron é a presença de uma raiz unitária contra a hipótese alternativa de a série ser estacionária; os valores críticos para o teste Phillips-Perron com constante e tendência a 1\% de significância são -3,488 e -4,018, respectivamente. Os valores críticos a 5\% de significância são $-2,886$ e $-3,441$ e os valores a $10 \%$ de significância são $-2,576$ e -3,141, considerando que a hipótese nula no teste KPSS indica a série ser estacionária, enquanto a hipótese alternativa aponta para presença de uma raiz unitária, em que os valores críticos para o teste KPSS com constante e tendência a $1 \%$ de significância 0,739 e 0,216 . Os valores a $5 \%$ de significância são

0,463 e 0,146 e, para o nível de $10 \%$ de significância, são 0,347 e 0,119. Os números de defasagens foram escolhidos pelo critério Bayesian Information Criterion (BIC). ${ }^{* * *},{ }^{* *} \mathrm{e}^{*}$ indicam rejeição da hipótese nula a 1\%, 5\% e $10 \%$, respectivamente. 
Em análise similar, verifica-se que a variável preço praticado pelo atacado apresenta raiz unitária em nível, para todas a cidades, quando aplicados os testes de Phillips-Perron e de KPSS, tanto com, quanto sem a inclusão da tendência determinística. Entretanto, com a aplicação da primeira diferença, ambos os testes de verificação de estacionariedade indicaram que a variável preço no atacado se mostrou estacionária; desta forma, apresentando ordem de integração um.

Tabela 4 - Resultados dos testes de raiz unitária para as séries de preço no atacado

\begin{tabular}{|c|c|c|c|c|c|c|}
\hline \multirow[t]{2}{*}{ Cidades } & \multicolumn{4}{|c|}{ Em nível } & \multicolumn{2}{|c|}{ Em primeira diferença } \\
\hline & $P P$ & PP+trend & KPSS & KPSS+trend & $P P$ & KPSS \\
\hline Alvorada & $-0,113$ & $-1,916$ & $6,32^{* * *}$ & $1,56^{\star \star *}$ & $-14,460^{\star * *}$ & 0,137 \\
\hline Bagé & $-0,102$ & $-1,835$ & $6,36^{* * *}$ & $1,71^{\star \star *}$ & $-13,965^{\star * *}$ & 0,142 \\
\hline Cachoeirinha & $-0,47$ & $-2,173$ & $6,27^{* * *}$ & $1,57^{\star \star *}$ & $-12,306^{\star \star \star}$ & 0,11 \\
\hline Canoas & $-0,288$ & $-1,943$ & $6,08^{* * *}$ & $1,54^{* * *}$ & $-12,381^{* * *}$ & 0,143 \\
\hline Caxias do Sul & $-0,147$ & $-1,826$ & $6,36^{* * *}$ & $1,65^{\star \star \star}$ & $-10,608^{* * *}$ & 0,175 \\
\hline Erechim & $-0,037$ & $-1,716$ & $6,32^{* \star *}$ & $1,65^{\star \star *}$ & $-10,880^{\star \star \star}$ & 0,191 \\
\hline Gravataí & $-2,168$ & $-2,031$ & $6,15^{* * *}$ & $1,58^{\star \star *}$ & $-12,843^{\star * *}$ & 0,182 \\
\hline Guaíba & $-0,867$ & $-2,779$ & $4,2^{\star * \star}$ & $0,99^{\star \star \star}$ & $-15,932^{\star \star \star}$ & 0,0706 \\
\hline Novo Hamburgo & $-0,554$ & $-2,28$ & $6,19^{\star * *}$ & $1,49^{\star \star \star}$ & $-11,842^{\star \star \star}$ & 0,111 \\
\hline Passo Fundo & $-0,961$ & $-3,163^{*}$ & $4,39^{* * *}$ & $1,1^{* \star *}$ & $-17,982^{* \star *}$ & 0,0612 \\
\hline Pelotas & $-0,014$ & $-1,74$ & $6,33^{* * *}$ & $1,67^{\star \star \star}$ & $-10,376^{\star \star \star}$ & 0,202 \\
\hline Porto Alegre & $-0,178$ & $-1,872$ & $6,33^{* * *}$ & $1,63^{* * *}$ & $-11,616^{\star \star \star}$ & 0,16 \\
\hline Rio Grande & $-0,98$ & $-2,927$ & $3,11^{* * *}$ & $1,08^{\star \star *}$ & $-13,717^{\star * \star}$ & 0,0779 \\
\hline Santa Cruz do Sul & 0,072 & $-1,707$ & $6,37^{* * *}$ & $1,64^{\star \star \star}$ & $-11,830^{\star \star \star}$ & 0,196 \\
\hline Santa Maria & $-0,088$ & $-1,822$ & $6,38^{* * *}$ & $1,63^{\star \star *}$ & $-11,191^{\star * *}$ & 0,175 \\
\hline São Leopoldo & $-0,776$ & $-2,757$ & $4,19^{* * *}$ & $1,08^{* \star *}$ & $-18,192^{\star \star *}$ & 0,0857 \\
\hline Sapucaia do Sul & $-0,654$ & $-2,378$ & $6,36^{\star * *}$ & $1,53^{\star \star *}$ & $-12,207^{\star * *}$ & 0,092 \\
\hline Uruguaiana & $-0,538$ & $-2,316$ & $6,49^{\star \star \star}$ & $1,64^{\star \star *}$ & $-14,783^{* * *}$ & 0,0842 \\
\hline Viamão & $-0,209$ & $-1,965$ & $6,35^{\star * *}$ & $1,65^{\star \star \star}$ & $-13,753^{\star \star \star}$ & 0,134 \\
\hline
\end{tabular}

Fonte: Resultados da pesquisa (2020).

Nota: A hipótese nula a ser testada pelo Phillips-Perron (PP) é a de uma raiz unitária contra a hipótese alternativa de a série ser estacionária. Os valores críticos para o teste Phillips-Perron com constante e tendência a 1\% de significância são $-3,488$ e -4,018, respectivamente. Os valores críticos a 5\% de significância são $-2,886$ e $-3,441$, e os valores a $10 \%$ de significância são -2,576 e -3,141, considerando que a hipótese nula, no teste KPSS, indica a série ser estacionária, enquanto a hipótese alternativa aponta para presença de uma raiz unitária, em que os valores críticos para o teste KPSS com constante e tendência a $1 \%$ de significância 0,739 e 0,216 . Os valores a $5 \%$ de significância são 0,463 e 0,146 e para o nível de $10 \%$ de significância são 0,347 e 0,119 , os números de defasagens foram escolhidos pelo critério Bayesian Information Criterion (BIC). Os símbolos de ${ }^{* * *},{ }^{* *} \mathrm{e}^{*}$ indicam rejeição da hipótese nula a 1\%, $5 \%$ e $10 \%$, respectivamente.

Após a identificação da ordem de integração das séries, aplicou-se o teste de cointegração. A indicação de relacionamento de longo prazo entre as series é um dos critérios que possibilita a estimação do mecanismo de correção de erros. Por sua vez, a não ocorrência de cointegração supõe que as diferenças no modelo de transmissão de preços, entre os choques positivos e negativos, seriam permanentes, e os preços, no atacado e no varejo, poderiam se distanciar, conforme Meyer e Von Cramon-Taubadel (2004).

Logo, sendo o objetivo identificar se o preço da gasolina no varejo causa, no sentido de Engle-Granger, o preço do atacado "upstream", a identificação de cointegração é condição necessária. A partir disso, aplicouse o teste de cointegração de Engle-Granger com a variável preço no atacado como variável dependente e a variável preço no varejo como variável exógena. Os resultados, conforme Tabela 5 , indicam que todas as cidades apresentaram cointegração, exceto para Erechim. Condição que levou a exclusão desta cidade à análise aplicação do mecanismo de correção de erros.

Seguindo o processo de ajuste, realizaram-se os testes de diagnóstico. A presença de autocorrelação faz com que a variância dos estimadores fique indeterminada, o que leva à redução de eficiência entre os estimadores; já a heterocedasticidade é causada pelas diferentes variâncias no decorrer da série temporal, situação que igualmente implica redução de eficiência dos estimadores (GREENE, 2003).

A presença de autocorrelação foi verificada pela aplicação do teste Ljung-Box, cujos resultados evidenciaram que apenas as cidades de Caxias do Sul, Gravataí, Pelotas, Porto Alegre e Santa Maria não indicaram presença de correlação serial, enquanto que, para as demais cidades, se constatou a presença de 
autocorrelação serial (Tabela 5). A heterocedasticidade foi testada por meio do teste de Breusch-Pagan que apresentou resultados de igualdade de variância apenas às cidades de Caxias do Sul, Passo Fundo, Pelotas, Porto Alegre, Santa Maria, São Leopoldo e Sapucaia do Sul, enquanto as demais apresentaram resultados heterocedásticos (Tabela 5).

Em caso de identificação de ambos os problemas, a correção ocorreu com a utilização do estimador Newey-West, o qual, por meio de estimativas robustas, corrige tanto a heterocedasticidade quanto a autocorrelação.

Tabela 5 - Resultados dos testes de cointegração, autocorrelação e heterocedasticidade.

\begin{tabular}{cccc}
\hline Cidades & Engle-Granger & Ljung-Box & Breusch-Pagan \\
\hline Alvorada & $-7,909^{* * *}$ & $12,00^{* * *}$ & $35,77^{* * *}$ \\
Bagé & $-5,544^{* * *}$ & $59,41^{* * *}$ & $15,79^{* * *}$ \\
Cachoeirinha & $-7,691^{* * *}$ & $24,02^{* * *}$ & $124,40^{* * *}$ \\
Canoas & $-7,192^{* * *}$ & $10,95^{* * *}$ & $27,91^{* * *}$ \\
Caxias do Sul & $-4,488^{* * *}$ & 2,77 & 0,7 \\
Erechim & $-2,912$ & - & - \\
Gravataí & $-7,252^{* * *}$ & 2,45 & $3,81^{*}$ \\
Guaíba & $-8,085^{* * *}$ & $30,01^{* * *}$ & $3,86^{* *}$ \\
Novo Hamburgo & $-7,150^{* * *}$ & $40,76^{* * *}$ & $16,57^{* * *}$ \\
Passo Fundo & $-7,958^{* * *}$ & $40,55^{* * *}$ & 0,2 \\
Pelotas & $-3,094^{*}$ & 0,04 & 0,76 \\
Porto Alegre & $-7,860^{* * *}$ & 1,32 & 0,03 \\
Rio Grande & $-7,123^{* * *}$ & $39,70^{* * *}$ & $11,40^{* * *}$ \\
Santa Cruz do Sul & $-3,963^{* * *}$ & $22,47^{* * *}$ & $9,58^{* * *}$ \\
Santa Maria & $-4,112^{* * *}$ & 0,53 & 0,42 \\
São Leopoldo & $-7,845^{* * *}$ & $27,06^{* * *}$ & 0,83 \\
Sapucaia do Sul & $-7,231^{* * *}$ & $28,36^{* * *}$ & 12,76 \\
Uruguaiana & $-7,837^{* * *}$ & $43,51^{* * *}$ & $63,48^{* * *}$ \\
Viamão & $-6,511^{* * *}$ & $54,58^{* * *}$ & $4,23^{* *}$
\end{tabular}

Fonte: Resultados da pesquisa (2020).

Nota: O teste de Engle Granger tem como hipótese nula a não cointegração dos processos, enquanto a sua hipótese alternativa é a cointegração dos processos. ${ }^{* * *}{ }^{* *}{ }^{*}{ }^{*}$ indicam rejeição da hipótese nula a $1 \%, 5 \%$ e $10 \%$,

respectivamente. Para o teste de autocorrelação de $L j u n g-B o x$, a hipótese nula representa que os resíduos são identicamente distribuídos "sem a presença de autocorrelação", já a hipótese alternativa aponta para os resíduos não serem identicamente distribuídos "presença de autocorrelação". Já para o teste Breusch-Pagan, a hipótese nula indica que a variância é homocedástica e a hipótese alternativa indica que a variância é heterocedástica. ${ }^{* * *},{ }^{* *} \mathrm{e}$ * indicam rejeição da hipótese nula a $1 \%, 5 \%$ e $10 \%$, respectivamente.

Definidas as propriedades das séries e corrigidos os problemas, estimou-se o mecanismo de correção de erros para as 18 cidades que atenderam aos critérios da modelagem de determinação da transmissão de preços (Tabela 6).

Tabela 6 - Resultados dos coeficientes da estimação e dos testes de identificação de assimetria para as cidades analisadas

\begin{tabular}{|c|c|c|c|c|c|c|c|}
\hline Cidades & $\Delta P_{i, t-1}^{A}$ & $\alpha_{l}^{+}$ & $\alpha_{l}^{-}$ & $\boldsymbol{\alpha}_{l}^{+}=\boldsymbol{\alpha}_{\boldsymbol{l}}^{-}$ & $\lambda^{+}$ & $\lambda^{-}$ & $\lambda^{+}=\lambda^{-}$ \\
\hline Alvorada & $-0,129$ & $0,182^{* *}$ & $0,128^{\star *}$ & $3,7^{*}$ & $0,473^{* *}$ & $0,474^{\star \star}$ & 0,03 \\
\hline Bagé & 0,032 & $0,121^{*}$ & $0,076^{*}$ & 2,37 & $-0,105$ & $-0,349$ & 0,23 \\
\hline Cachoeirinha & $-0,110$ & $0,222^{\star *}$ & $0,145^{\star *}$ & $4,56^{\star \star}$ & $0,695^{\star *}$ & $0,542^{*}$ & 0,02 \\
\hline Canoas & $-0,044$ & $0,165^{\star}$ & $0,109^{*}$ & $3,26^{\star}$ & $0,790^{* * *}$ & 0,071 & $4,24^{\star \star}$ \\
\hline Caxias do Sul & $-0,013$ & $0,214^{* * *}$ & $0,122^{\star \star \star}$ & $12,03^{\star \star \star}$ & 0,371 & 0,543 & 0,00 \\
\hline Gravataí & 0,020 & $0,097^{\star \star}$ & $0,155^{\star \star \star}$ & $6,24^{\star \star}$ & 0,483 & $0,461^{\star *}$ & 0,04 \\
\hline
\end{tabular}




\begin{tabular}{|c|c|c|c|c|c|c|c|}
\hline Cidades & $\Delta P_{i, t-1}^{A}$ & $\alpha_{l}^{+}$ & $\alpha_{l}^{-}$ & $\alpha_{l}^{+}=\alpha_{l}^{-}$ & $\lambda^{+}$ & $\lambda^{-}$ & $\lambda^{+}=\lambda^{-}$ \\
\hline Guaíba & 0,004 & 0,105 & 0,085 & 2,42 & 0,064 & $0,430^{\star *}$ & 2,21 \\
\hline Novo Hamburgo & 0,02 & $0,131^{\star *}$ & $0,091^{* *}$ & $4,41^{\star \star}$ & $0,739^{\star \star *}$ & 0,213 & 1,39 \\
\hline Passo Fundo & 0,029 & $0,171^{*}$ & $0,129^{*}$ & 2,63 & $-0,021$ & $0,147^{*}$ & 0,37 \\
\hline Pelotas & 0,114 & $0,263^{* * *}$ & $0,148^{* * *}$ & $12,81^{\star \star \star}$ & 0,662 & $0,222^{* *}$ & $4,93^{\star \star}$ \\
\hline Porto Alegre & $-0,029$ & $0,204^{* * *}$ & $0,123^{\star * *}$ & $5,39^{\star \star}$ & $0,6261^{* *}$ & $1,57^{\star * *}$ & 2,48 \\
\hline Rio Grande & 0,066 & 0,043 & 0,038 & $2,87^{\star}$ & $0,219^{* *}$ & $0,060^{*}$ & $3,60^{*}$ \\
\hline Santa Cruz do Sul & 0,007 & 0,180 & 0,103 & $2,88^{\star}$ & $1,002^{* \star *}$ & 0,766 & 0,22 \\
\hline Santa Maria & $-0,009$ & $0,222^{* * *}$ & $0,124^{* * *}$ & $9,61^{* \star *}$ & 0,210 & 0,854 & 0,94 \\
\hline São Leopoldo & $-0,060$ & $0,194^{* *}$ & $0,147^{\star *}$ & $5,10^{\star \star}$ & 0,061 & $0,207^{*}$ & 0,14 \\
\hline Sapucaia do Sul & $-0,003$ & $0,167^{\star *}$ & $0,116^{\star \star}$ & $3,93^{\star *}$ & $0,386^{\star *}$ & 0,252 & 0,05 \\
\hline Uruguaiana & 0,037 & 0,1160 & 0,081 & 1,64 & 0,005 & $0,558^{\star \star *}$ & $13,63^{*}$ \\
\hline Viamão & $-0,042$ & $0,233^{* * *}$ & $0,149^{* * *}$ & $5,87^{\star \star}$ & $0,385^{\star}$ & 0,210 & 0,05 \\
\hline
\end{tabular}

Fonte: Resultados da pesquisa (2020).

Nota 2: ${ }^{* * *},{ }^{* *} \mathrm{e}{ }^{*}$ indicam significância dos coeficientes estimados a $1 \%, 5 \%$ e $10 \%$, respectivamente.

Nota 2: A hipótese nula, de curto prazo $\boldsymbol{\alpha}_{l}^{+}=\boldsymbol{\alpha}_{l}^{-}$e longo prazo $\lambda^{+}=\lambda^{-}$, aponta transmissão simétrica dos preços, enquanto a hipótese alternativa aponta a transmissão assimétrica de preços. ${ }^{* * *},{ }^{* *} \mathrm{e}^{*}$ indicam significância a $1 \%, 5 \% \mathrm{e}$ $10 \%$, respectivamente.

Verifica-se a presença de transmissão assimétrica dos preços da gasolina no curto prazo para $77,77 \%$ das cidades analisadas como é exposto na figura 6, exceção fez-se somente às cidades de Bagé, Guaíba, Passo Fundo e Uruguaiana, as quais apresentaram transmissão simétrica de preços. Logo, constata-se que, para grande parte das cidades estudadas, as variações ocorridas, nos postos de combustíveis, são seguidas de aumentos dos preços de diferentes magnitudes pelos distribuidores, sendo que a grande maioria que apresentou assimetria, configurando-se, assim, com uma assimetria positiva; por outro lado, a única cidade que teve assimétrica negativa, de curto prazo, foi a cidade de Gravataí.

Figura 6 - Cidades que apresentaram transmissão simétrica e assimétrica de curto prazo

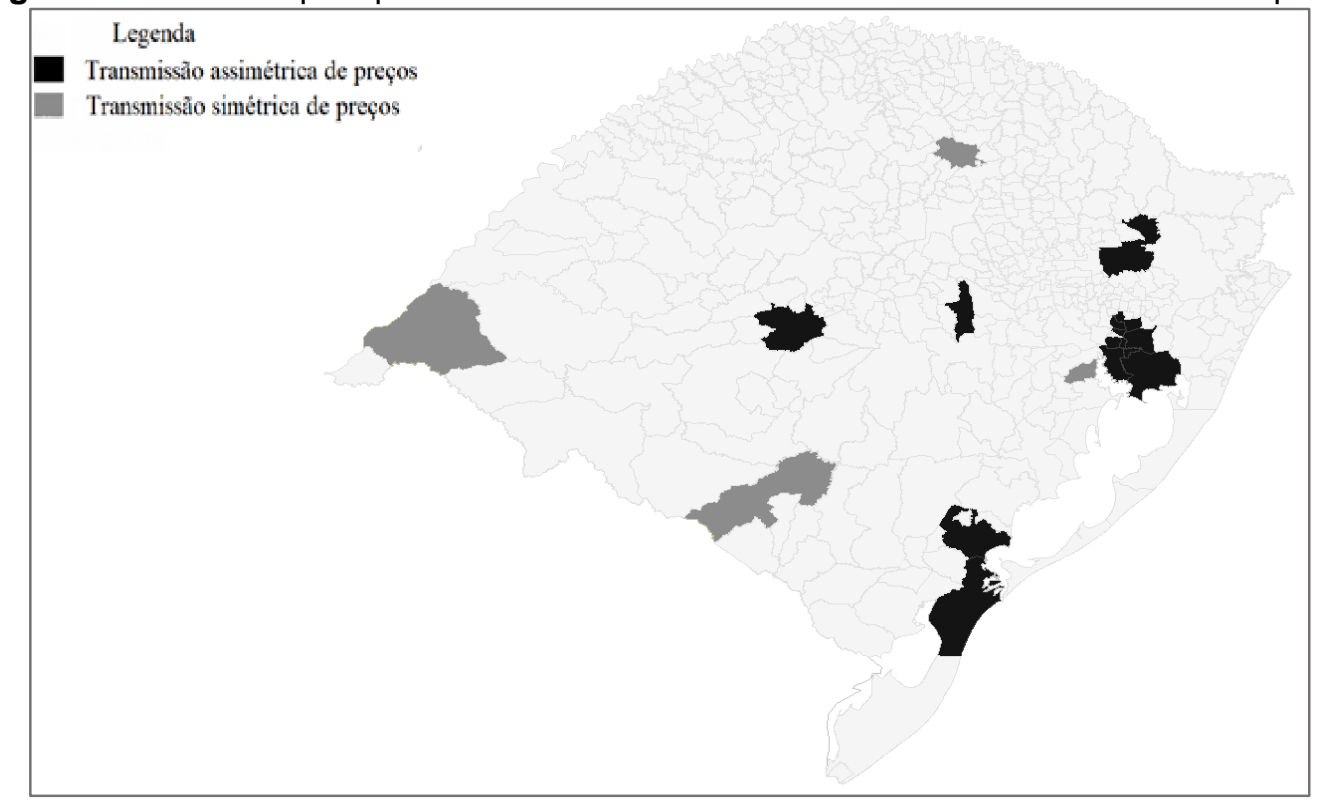

Fonte: Resultados da pesquisa (2020).

A ocorrência de assimetria de curto prazo decorre da percepção dos consumidores dos possíveis aumentos nos preços no mercado nacional (distribuidoras). Com isso, elevam o consumo antes da alteração de preços nos postos de combustíveis como forma de se proteger de um futuro aumento do preço, de acordo com Salvini (2016). Este aumento no nível de consumo leva a um esgotamento dos estoques dos postos de combustíveis, obrigando os proprietários a elevar o preço do combustível como resposta ao choque da demanda.

Uma outra possível justificativa é a baixa ocorrência de concorrentes próximos, como exposto por Cardoso et al. (2016), que encontrou resultados de que a assimetria era predominantemente positiva, e que 
segundo ele, os postos na busca por maiores margens de lucro repassariam os aumentos com uma maior intensidade, assim como o fato de a escassez de concorrentes próximos ser um dos motivos da presença de assimetria.

Já a transmissão assimétrica de longo prazo ocorre em aproximadamente $22,22 \%$ das cidades analisadas como se observa na figura 7, especificamente, nas cidades de Canoas, Pelotas, Rio Grande e Uruguaiana. Nessas, o reajuste dos preços da gasolina praticada pelos postos de combustíveis difere daquele de repasse dos distribuidores.

Umas das possíveis justificativas à presença de assimetria positiva de longo prazo é, nas cidades Canoas, Pelotas e Rio Grande, seguindo a discussão introduzida por decorreria de prejuízos nos momentos de elevação dos preços no atacado. Assim, de modo a compensar esses prejuízos, os postos não estariam repassando as variações negativas do preço do atacado, aumentando sua margem de lucro como forma de recuperar os prejuízos dos períodos anteriores.

Para o caso particular de Uruguaia, poderia ter implicações maiores devido ao fato de, no curto prazo, a cidade apresentar simetria nos repasses, mas, no longo prazo, ela apresenta assimetria negativa. A possível justificativa para este caso é o fato de Uruguaiana fazer fronteira com a argentina. Esse fato leva os consumidores a comparar os preços, fazendo optar por cruzarem a fronteira na busca de preços menores prazo, como relatado pela reportagem da Globo (2014). Uma dessa implicações seria a queda na demanda para os postos localizados em Uruguaiana, fazendo, nesse caso, os donos de postos repassarem as variações negativas com maior intensidade de modo a competir com os postos Argentinos.

Figura 7 - Cidades que apresentaram transmissão simétrica e assimétrica de longo prazo

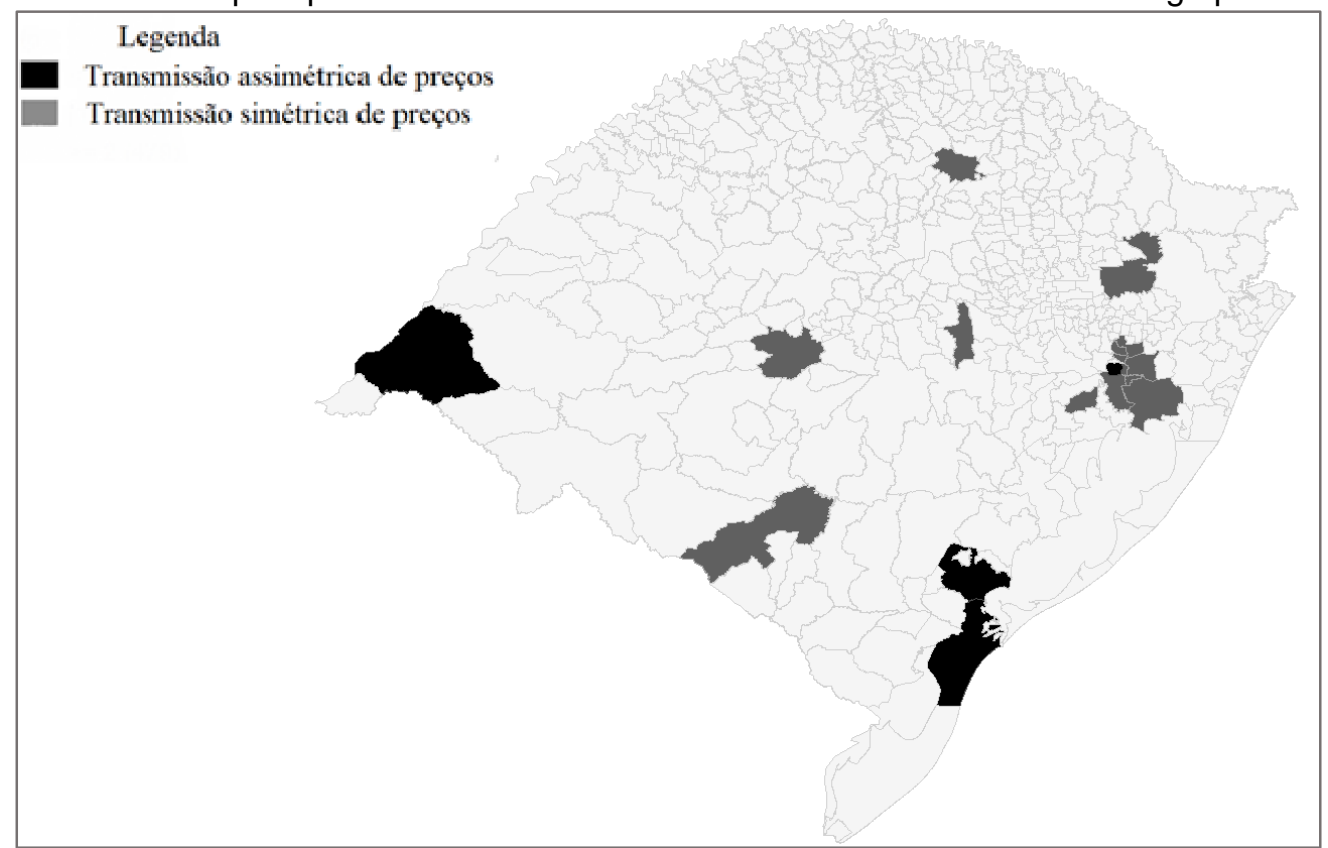

Fonte: Resultados da pesquisa (2020).

Outro aspecto relevante para o estado no Rio Grande do Sul quanto à transmissão assimétrica de preços reside no fato de que as cidades que possuem indústria de refinamento dos combustíveis, caso de Canoas, na região metropolitana de Porto Alegre e responsável por grande parte do fornecimento de gasolina do estado, e da cidade de Rio Grande, apresentaram assimetria tanto para o curto como para o longo prazo. Resultado que reforça o argumento de que a localização da refinaria influencia os postos a tomar medidas de reajustes antecipadas aos aumentos dos preços nos distribuidores.

\section{CONCLUSÕES}

O estudo buscou identificar a ocorrência de assimetria no repasse de preços da gasolina para as maiores cidades do Rio Grande do Sul, entre 2005 e 2018, considerando a transmissão dos preços do varejo para o atacado upstream. Os resultados apontam que, para o curto prazo, $77,77 \%$ das cidades analisadas apresentaram algum tipo de transmissão assimétrica dos preços, enquanto que, para o longo prazo, 22,22\% das cidades analisadas.

Tais evidências indicam que grande parte das cidades analisadas apresentam algum tipo de transmissão assimétrica na definição dos preços da gasolina, exceção ocorre nas cidades de Bagé, Guaíba 
e Passo Fundo, que não apresentaram nenhum tipo de assimetria nos reajustes dos preços do combustível. Isso permite concluir que as maiores cidades do Rio Grande do Sul apresentam problemas informacionais quanto ao repasse das variações aos preços da gasolina com potenciais perdas aos consumidores.

Esses resultados corroboram as evidências de transmissão assimétrica de preços de combustíveis, sendo a assimetria de curto prazo encontrada à maioria das cidades e relacionada a problemas que envolvem a capacidade de estoques dos postos que não permitem o repasse das variações no curto prazo, como também a racionalidade dos consumidores em antecipar o consumo a fim de se proteger de possíveis elevações dos preços. Comportamento esse que leva a aumentos na demanda e posterior elevações nos preços como resposta às mudanças não previstas na demanda.

Ainda, constatou-se que 0 fato de a refinaria se encontrar geograficamente próximo ao local de distribuição não limitou a ocorrência de transmissões assimétricas de preços da gasolina, não sendo, assim, um fator determinante para a transmissão simétrica de preços. Tanto a cidade de Canoas, onde se encontra a refinaria Alberto Pasqualini, como na cidade de Rio Grande, onde se localiza a refinaria Petróleo Riograndense, foram as que apresentaram os maiores níveis de assimetrias na transmissão dos preços.

Conquanto os resultados tenham demonstrado informações relevantes, cabe ressaltar que os achados são específicos à metodologia, ao tempo e à região. Assim, há espaço para novas pesquisas acerca da transmissão assimétrica de preços. Para novos estudos, sugere-se a ampliação das cidades como também a análise mais detalhada daquelas que apresentaram assimetria, buscando verificar se a existência de assimetria ocorre em todos os postos de combustíveis ou se este processo ocorre de maneira isolada.

Embora os resultados tenham permitido identificar o mecanismo de repasse dos reajustes de preços da gasolina nas maiores cidades do Rio Grande do Sul, alguns aspectos limitaram as análises, caso da característica da base de dados e da ausência de informação quanto ao número de postos que pertencem ao mesmo grupo empresarial, situação que dificulta a análise, especificamente, para o longo prazo. Assim, como forma de ampliar as evidências, sugere-se o desenvolvimento de estudos que venham a trabalhar com outros tipos de combustíveis, como álcool, diesel e gás natural veicular.

\section{REFERÊNCIAS}

ANP. Anuário Estatístico Brasileiro do Petróleo, Gás Natural e Biocombustíveis 2018. Agência Nacional do Petróleo, Gás Natural e Biocombustíveis. Rio de Janeiro. 2018a.

ANP. Nota técnica Nº02/2019/ assessoria DG. Agência Nacional do Petróleo, Gás Natural e Biocombustíveis. Rio de Janeiro, p. 2-3. 2019b.

BALKE, N. S., BROWN, S. P. A.; YUCEL, M. K. (1998) Crude oil and gasoline prices: an asymmetric relationship Economic and Financial Policy Review 1: 2-11.

CANÊDO-PINHEIRO, M. Assimetrias na transmissão dos preços dos combustíveis: o caso do óleo diesel no Brasil. Revista Brasileira de Economia, v. 66, n. 4, p. 469-490, 2012.

Cardoso, L.; Bittencourt, M.; Irwin, E.. Price asymmetry and retailers heterogeneity in Brazilian gas stations. ANPEC-44 ${ }^{\circ}$ Encontro (2016), pp. 1-20

CBIE. cbie.com.b. Centro Brasileiro de Infraestrutura, 2019. Disponivel em: < https://cbie.com.br/category/artigos/>. Acesso em: 22 OUTUBRO 2019.

CHEN, N. Modelling Demand for Rail Transport with Dynamic Econometric Approaches. International Review of Business Research Papers, v.3, p. 85-96, 2007.

DAROIT, F. Valor do litro da gasolina chega a variar mais de R\$ 0,70 na Região Metropolitana. Gauchazh, 2019. Disponivel em: <https://gauchazh.clicrbs.com.br/porto-alegre/noticia/2019/07/valor-do-litro-da-gasolina-chega-a-variarmais-de-r-070-na-regiao-metropolitana-cjy6a4a7e02bj01msv6i76um4.html>. Acesso em: 15 outubro 2019

ENGLE, R. F.; GRANGER, C. W. J. Cointegration and error correction: representation, estimation, and testing. Econometrica, v. 55, p. 251-276, march 1987. ISSN 2.

ESTATÍSTICA, F. D. E. E. Fundação de Economia e Estatística Siegfried Emanuel Heuser. Fundação de Economia e Estatística, 2019. Disponivel em: <https://arquivofee.rs.gov.br/indicadores/populacao/apresentacao/>. Acesso em: 20 AGOSTO 2019.

FREY, G.; MANERA, M. ECONOMETRIC MODELS OF ASYMMETRIC PRICE TRANSMISSION. JOURNAL OF ECONOMIC SURVEYS, Malden, v. 21, p. 349-415, 2007. ISSN 2.

GLOBO. Motoristas do RS cruzam fronteira para abastecer carros na Argentina. G1, 2014. http://g1.globo.com/rs/riogrande-do-sul/noticia/2014/11/motoristas-do-rs-cruzam-fronteira-para-abastecer-carros-naargentina.html\#: :text=Motoristas\%20do\%20RS\%20cruzam\%20fronteira,Rio\%20Grande\%20do\%20Sul\%20\%7C\%20G1 \&text=Condutores\%20optaram\%20por\%20enche. Acesso em: 1 maio 2021.

GREENE, W. H. ECONOMETRIC ANALYSIS. 5. ed. New York : Pearson Education, 2003.

MADDALA, G. S.; KIM, I.-M. Unit roots, co integration, and structural change. Cambridge University. New York, p. 387-418. 1998. 
MEYER, J.; CRAMON-TAUBADEL, S. V. Asymmetric Price Transmission: A Survey. Journal of Agricultural Economics, v. 55, p. 581-611, setembro 2004. ISSN 3.

PETROBRAS. Copyright Petrobras 2019. Copyright Petrobras 2019, 2019. Disponivel em:

<https://petrobras.com.br/pt/nossas-atividades/areas-de-atuacao/exploracao-e-producao-de-petroleo-e-gas/Acesso em: 22 outubro 2019.

RUSSEL, D.; MACKINNON, G. J. Econometric Theory and Methods. Oxford University Press, 2004. Econometric Theory.

SALTON, A.; MATTOS, L. B. D. Transmissão assimétrica de preços no mercado brasileiro de etanol. XVI Encontro Nacional da Associação Brasileira de Estudos Regionais e Urbanos. Caruaru: [s.n.]. 2018.

SALVINI, R. R. INVESTIGANDO A ASSIMETRIA NA TRANSMISSÃO DOS PREÇOS DOS COMBUSTíVEIS NO ESTADO DE SÃO PAULO. Universidade de São Paulo Escola Superior de Agricultura Luiz de Queiroz. Piracicaba, p. 75. 2016.

SARGAN, J. D. Three-stage least-squares and full maximum likelihood estimates. Econometrica: Journal of the Econometric Society, p. 77-81, 1964.

Silva, A. S.; Vasconcelos, C. R.; Vasconcelos, S. P.; Mattos, R. Transmissão assimétrica de Preços: 0 caso do mercado de gasolina a varejo nos municípios do Brasil. Programa de Pós - Graduação em Economia Aplicada FE/UFJF. Juiz de Fora, 2011

VATTO, T. V. Medidas de memória Ionga em séries. Universidade de Brasília. Brasilia , p. 43-60. 2014. 